\title{
Animals in Healthcare Facilities: Recommendations to Minimize Potential Risks
}

\author{
Rekha Murthy, MD ${ }^{1}$ Gonzalo Bearman, MD, MPH $;^{2}$ Sherrill Brown, $\mathrm{MD} ;{ }^{3}$ Kristina Bryant, $\mathrm{MD} ;{ }^{4}$ Raymond Chinn, MD ${ }^{5}$ \\ Angela Hewlett, MD, MS; ${ }^{6}$ B. Glenn George, JD; ${ }^{7}$ Ellie J.C. Goldstein, MD; ${ }^{8}$ Galit Holzmann-Pazgal, MD; ${ }^{9}$ \\ Mark E. Rupp, MD; ${ }^{10}$ Timothy Wiemken, PhD, CIC, MPH; ${ }^{4}$ J. Scott Weese, DVM, DVSc, DACVIM; ${ }^{11}$ David J. Weber, MD, MPH ${ }^{12}$
}

\section{P URPOSE}

Animals may be present in healthcare facilities for multiple reasons. Although specific laws regarding the use of service animals in public facilities were established in the United States in 1990, the widespread presence of animals in hospitals, including service animals to assist in patient therapy and research, has resulted in the increased presence of animals in acute care hospitals and ambulatory medical settings. The role of animals in the transmission of zoonotic pathogens and cross-transmission of human pathogens in these settings remains poorly studied. Until more definitive information is available, priority should be placed on patient and healthcare provider safety, and the use of standard infection prevention and control measures to prevent animal-to-human transmission in healthcare settings. This paper aims to provide general guidance to the medical community regarding the management of animals in healthcare (AHC). The manuscript has four major goals:

1. Review and interpret the medical literature regarding risks and evidence for animal-to-human transmission of pathogens in the healthcare setting, along with the potential benefits of animal-assisted activities in healthcare.

2. Review hospital policies related to AHC, as submitted by members of the SHEA Guidelines Committee.

3. Summarize a survey that assessed institutional AHC policies.

4. Offer specific guidance to minimize risks associated with the presence of AHC settings.

Recommendations for the safe oversight and management of AHC should comply with legal requirements and minimize the risk of transmission of pathogens from animals to humans when animals are permitted in the healthcare setting. Although little published literature exists on this topic, we provide guidance on the management of AHC in four categories: animal-assisted activities, service animals, research animals, and personal pet visitation. Institutions considering these programs should have policies that include well-organized communication and education directed at healthcare personnel (HCP), patients, and visitors. Appropriately designed studies are needed to better define the risks and benefits of allowing animals in the healthcare setting for specific purposes.

\section{B A C K G R O U N D}

\section{The Role of Animals in Healthcare Settings (AHC)}

People come into contact with animals in a variety of settings including households (pets), occupational exposure (veterinarians, farmers, ranchers, and forestry workers), leisure pursuits (hunting, camping, and fishing), petting zoos, and travel to rural areas. Pet ownership is common in the United States. A national poll of pet owners revealed that in 2013-2014, 68\% of US households included a pet with the number of households owning specific animals as follows: dogs 56.7 million, cats 45.3 million, freshwater fish 14.3 million, birds 6.9 million, small animals 6.9 million, reptiles 5.6 million, horses 2.8 million, and saltwater fish 1.8. ${ }^{1}$

Patients in healthcare facilities come into contact with animals for 2 main reasons: the use of animals for animal-assisted activities (animal-assisted activities encompass "pet therapy," "animal-assisted therapy," and pet volunteer programs) and the use of service animals such as guide dogs for the sight impaired. Other reasons for contact with AHC include the use of animals in research or education, and personal pet visits to their owners in the hospital (personal pet visitation). Risks to patients from exposure to animals in the healthcare setting may be associated with transmission of pathogens through

Affiliations: 1. Cedars-Sinai Medical Center, Los Angeles, California; 2. Virginia Commonwealth University, Richmond, Virginia; 3. Kaiser Permanente Medical Center, Woodland Hills, California; 4. University of Louisville, Louisville, Kentucky; 5. Sharp Metropolitan Medical Campus, San Diego, California; 6. University of Nebraska Medical Center, Omaha, Nebraska; 7. UNC Health Care System and UNC School of Medicine, Chapel Hill, North Carolina; 8. David Geffen School of Medicine at UCLA, R.M. Alden Research Laboratory, Santa Monica, California; 9. University of Texas Medical School, Houston, Texas; 10. University of Nebraska Medical Center, Omaha, Nebraska; 11. University of Guelph Centre for Public Health and Zoonoses, Guelph, Ontario, Canada; 12. University of North Carolina, Chapel Hill, North Carolina.

Received December 18, 2014; accepted December 21, 2014; electronically published March 2, 2015

(c) 2015 by The Society for Healthcare Epidemiology of America. All rights reserved. 0899-823X/2015/3605-0001. DOI: 10.1017/ice.2015.15 
TA BLE 1. Selected Diseases Transmitted by Dogs Stratified by Transmission Route

\begin{tabular}{|c|c|}
\hline Transmission Route & Selected Diseases \\
\hline & Capnocytophaga canimorsus infection \\
\hline & Staphylococcus aureus, including methicillin-resistant strains \\
\hline & Streptococcus spp. Infection \\
\hline \multirow[t]{2}{*}{ Direct or indirect contact } & Flea bites, mites \\
\hline & Mites (Cheyletiellidae, Sarcoptidae) \\
\hline \multirow[t]{4}{*}{ Fecal-oral } & Campylobacteriosis (Campylobacter spp.) \\
\hline & Paratyphoid (Salmonella spp.) \\
\hline & Giardiasis (Giardia duodenalis) \\
\hline & Salmonellosis (Salmonella enterica subsp enterica serotypes) \\
\hline & $\begin{array}{l}\text { Fleas } \\
\text { - Dipylidium caninum } \\
\text { - Bartonella henselae }\end{array}$ \\
\hline
\end{tabular}

direct or indirect contact or, less likely, droplet/aerosol transmission (Table 1); however, insufficient studies are available to produce generalizable, evidence-based recommendations (Table 2); therefore, wide variations exist in policies and practice across healthcare institutions.

\section{Risks of Animals in Healthcare}

Few scientific studies have addressed the potential risks of animalto-human transmission of pathogens in the healthcare setting. Furthermore, because animals have, in general, been excluded from hospitals, experience gained by means of case reports and outbreak investigations is minimal (Table 2). However, general knowledge of zoonotic diseases, case reports, and limited research involving animals in healthcare facilities indicate cause for concern. For example, human strains of methicillin-resistant Staphylococcus aureus (MRSA) have increasingly been described in cats, dogs, horses, and pigs, with animals potentially acting as sources of MRSA exposure in healthcare facilities. ${ }^{2}$ MRSA is just one of many potential pathogens; a wide range of pathogens exist, including common healthcare-associated pathogens (eg, Clostridium difficile, multidrug-resistant enterococci), emerging infectious diseases (eg, extended spectrum $\beta$-lactamase (ESBL)producing Enterobacteriaceae), common zoonotic pathogens (eg, Campylobacter, Salmonella, and dermatophytes), rare but devastating zoonotic pathogens (eg, rabies virus), and pathogens associated with bites and scratches (eg, Pasteurella spp., Capnocytophaga canimorsus, and Bartonella spp.). ${ }^{2-7}$

This white paper represents an effort to analyze the available data and provide rational guidance for the management of animals in acute care and ambulatory medical facilities, including animal-assisted activities, service animals, research animals, and personal pet visitation. It describes the need for future studies to close the gaps in knowledge about animals in healthcare settings.

The term guidance deserves special emphasis: this document should not be viewed as an evidence-based guideline but as a set of practical, expert-opinion-based recommendations for a common healthcare epidemiology question, made in the absence of robust evidence to support practice. Much of the content is informational and most of the recommendations in this document should be viewed as suggested actions to consider in the absence of a recognized standard or regulation. Adoption and implementation is expected to occur at the discretion of individual institutions. When clear regulatory or legislative mandates exist related to AHC (eg, Americans with Disabilities Act), they are noted. Previous guidelines that have covered some of the issues addressed in this document include the "Guidelines for animal-assisted interventions in healthcare facilities" 3 and the "Centers for Disease Control and Prevention (CDC)/Healthcare Infection Control and Prevention Advisory Committee Guidelines for Environmental Infection Control in Health-Care Facilities."

In this document, we use the following definitions:

1. Animal-assisted activities: pet-therapy, animal-assisted therapy, and other animal-assisted activities. While these practices and their purposes may vary because these animals and their handlers are (or should be) specifically trained, they will be referred to as animal-assisted activities animals in this document. 
TABLE 2. Studies of Pathogens and Outbreaks Associated with Animals in Healthcare (AHC)

\begin{tabular}{ll}
\hline Author, Year, (Ref. No.) & Methodology \\
\hline Lefebvre, 2006 (64) & $\begin{array}{c}\text { Healthy visitation dogs (n, 102) assessed for } \\
\text { presence of zoonotic pathogens. }\end{array}$ \\
& \\
& \\
Scott, 1988 (65) & Staphylococcus aureus (MRSA) on a \\
& rehabilitation geriatric ward \\
Lyons, $1980(66)$ & nutbreak of Salmonella Heidelberg in a hospital \\
Richet, 1991 (67) & Outbreak of Rhodococcus (Gordona) bronchialis \\
& sternal surgical site infections after coronary \\
& artery bypass surgery
\end{tabular}

Chang, 1998 (68)

Mossovitch, 1986 (69), Snider, $1993(70)$
An evaluation of a large outbreak of Malassezia pachydermatis in an intensive care nursery
Findings

Zoonotic agents isolated from 80 percent of animals including: toxigenic Clostridium difficile (40.1\%), Salmonella spp. (3\%), extended spectrum betalactamase or cephaloporinase E. coli (4\%), Pasteurella spp. (29\%), Malassezia pachydermatis (8\%), Toxocara canis (2\%), and Ancylostoma caninum (2\%)

Paws and fur of a cat that roamed the ward were heavily colonized by MRSA, and the cat was considered to be a possible vector for the transmission of MRSA

Outbreak traced to infected calves on a dairy farm where the mother of the index patient lived

Outbreak linked to a nurse whose hands, scalp, and vagina were colonized with the epidemic pathogen. Although cultures of neck-scruff skin of 2 of her 3 dogs were also positive, whether the animals were the source for colonizing the nurse or whether both the animals and nurse were colonized from an environmental reservoir could not be determined.

Isolates from all 15 case patients, 9 additional colonized infants, 1 healthcare worker, and 3 pet dogs owned by HCP had identical patterns of restriction fragmentlength polymorphisms (RFLPs).

The authors believed it likely that $M$. pachydermatis was introduced into the intensive care nursery from the healthcare worker's hands after being colonized from pet dogs at home and then persisted in the nursery through patient-to-patient transmission.

Patient infections were not benign and included 8 bloodstream infections, 2 urinary tract infections, 1 case of meningitis, and 4 asymptomatic colonizations.

Person-to-person transmission described; in neonatal intensive care unit outbreak, the source of infection in the neonatal intensive care unit outbreak was a nurse likely infected from her pet cat.
Multiple nosocomial outbreaks of Microsporum neonatal intensive care units.
2. Service animals: specifically defined in the United States under the Americans with Disabilities Act (ADA). ${ }^{9}$

3. Research animals: animals approved for research by the facility's Institutional Animal Care and Use Committee (IACUC).

4. Personal pet visitation: defined as a personal pet of a patient that is brought into the facility specifically to interact with that individual patient.

\section{Intended Use}

This document is intended to help acute care hospitals and ambulatory care facilities develop or modify policies related to animals based on their role (ie, animal-assisted activities, service animals, research animals, and personal pet visitation). It is not intended to guide the management of animals in other healthcare facilities such as assisted living, nursing homes, or extended care facilities.

\section{Society for Healthcare Epidemiology of America (SHEA) Writing Group}

The writing group consists of members of the SHEA Guidelines Committee, including those with research expertise on this topic, and invited members with related expertise in legal affairs, veterinary medicine, and infectious diseases.

\section{Key Areas Addressed}

We evaluated and summarized the literature and surveyed current practices in healthcare institutions around four major aspects of $\mathrm{AHC}$ :
1. Animal-assisted activities
2. Service animals
3. Animals in research
4. Personal pet visitation 


\section{Guidance and Recommendation Format}

Because this topic lacks the level of evidence required for a more formal guideline using the GRADE ${ }^{10}$ or a similar system for quantitating scientific papers, no grading of the evidence level is provided for individual recommendations. Guidance statements are provided for each of the sections identified in our review. Each guidance statement is based on a synthesis of the limited available evidence, theoretical rationale, practical considerations, analysis from a survey of SHEA membership and the SHEA Research Network, writing group opinion, and consideration of potential harm where applicable.

\section{REVIEW OF SUBMITTED POLICIES AND PROCEDURES HEALTHCARE FACILITIES}

We reviewed and compared hospital policies that were submitted from various institutions by the writing group and members of the SHEA Guidelines Committee and summarized the policies and procedures submitted by 23 healthcare facilities.

\section{Animal-Assisted Activities (Animal-Assisted or "Pet Therapy" Programs)}

Of the 23 facility policies submitted, 20 mentioned specific recommendations regarding animal-assisted activities. Most policies defined an animal-assisted activities animal as a personal pet that, with its owner or handler, provides comfort to patients in healthcare facilities. Dogs were almost exclusively utilized in animal-assisted activities; however, three policies allowed cats or miniature horses as animal-assisted activities animals. In general, animal-assisted activities animals were required to be $>1-2$ years of age, be fed a fully cooked diet for the preceding 90 days, not be in estrus, have lived with their owner in a residence for $>6$ months, and be housebroken, well mannered, obedient, easily controlled by voice command, and restrained by a short (4-6 feet) leash or lead. Eight policies required animals to be bathed and groomed within 24 hours prior to each visit, including brushing and filing of nails.

A total of 12 policies required a nationally or regionally recognized organization to approve the animal for registration and certification of its training as an animal-assisted activities animal. Almost all policies required that the animals undergo regular (usually annual) evaluation by a veterinarian confirming their good health, that they be up-to-date on vaccinations, and that they have normal laboratory work ( 2 policies required routine negative stool cultures prior to participation). Animal-assisted activities animals and handlers were routinely provided hospital-specific photo identification and uniforms identifying them as an animal-assisted activities team.

Some policies specifically excluded certain patients from animal-assisted activities (Table 3 ). These 14 policies required staff members, visitors, and patients to perform hand hygiene both prior to and after interacting with animal-assisted activities
TA BLe 3. Exclusion Criteria Cited by Hospital Policies Related to Animal-Assisted Activities

\begin{tabular}{lc}
\hline Type of Patient & $\begin{array}{c}\text { Policies Citing Listed } \\
\text { Exclusion Criteria } \\
(\mathrm{n}=20), \text { No. }(\%)\end{array}$ \\
\hline Isolation (contact/airborne/droplet, etc.) & $12(60)$ \\
Immunocompromised (definitions varied) & $6(30)$ \\
Allergy to animals & $5(25)$ \\
Fear of animals & $5(25)$ \\
Open wounds & $4(20)$ \\
Behavior or psychiatric disorder & $1(5)$ \\
\hline
\end{tabular}

animals. Some policies stated that during animal-assisted activities, a barrier such as a sheet or towel be placed between the animal and the patient, either on the bed over the bedding, on a chair, or on a lap. In addition, the animal-assisted activities animal handler was usually responsible for cleaning up after any potential spills or environmental contamination during a therapy animal visit.

\section{Service Animals}

A total of 18 hospitals submitted their policies on service animals (Table 4). Most policies mentioned that service animals are not pets, and a few institutions specified that comfort and companionship animals are not service animals. Although most policies specifically allowed dogs, some also allowed the use of cats and miniature horses. A few institutions considered emotional support and seizure alert animals to be service animals.

Requirements of service animals consistently included up-to-date vaccinations and certification of good health, and that service animals are required to be housebroken and under the control of the handler at all times, usually with a leash. Further, a physician order and permission from the Infection Prevention and Control Department were often required. In general, service animals were prohibited from drinking out of public water areas (eg, toilets, sinks), from having contact with persons with non-intact skin, and being kept overnight. Most policies clearly stated that care of the service animal was the complete responsibility of the patient, or his or her designee. Areas that policies often listed as off-limits included operating rooms, post-anesthesia areas, heart and vascular procedure rooms, intensive care units, family birthing areas, pharmacy, central sterile processing, food preparation areas, nurseries, medication rooms, diagnostic areas, dialysis units, playrooms, rooms where the patient has a roommate, rooms that house patients with documented animal allergies or phobias, and around patients with altered mental status or post-splenectomy patients. The policies for visitors with service animals were similar to those applicable to patients, although some healthcare facilities chose to prohibit service animals of visitors from intensive care units, oncology and transplant units, and from visiting patients on isolation 
TA вLE 4. Summary of Responses from Hospitals Submitting Policies and Procedures on Service Animals

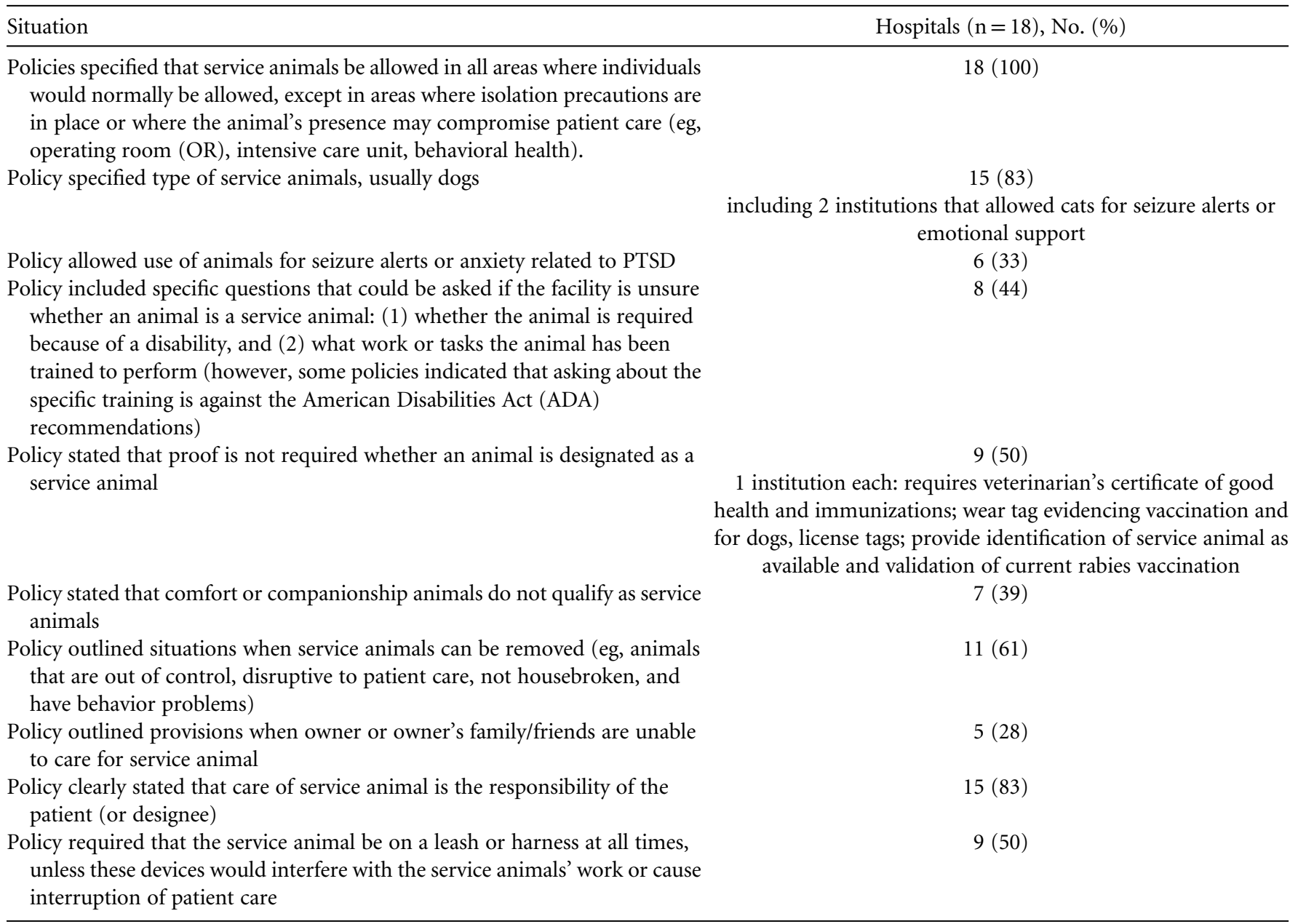

precautions. Many policies required immediate reporting of any injuries to the appropriate HCP (eg, risk management).

\section{Research Animals}

Only one-third of the policies discussed research animals. Those noted that although it is sometimes necessary for research animals to be present in patient care areas, every effort must be made to minimize interactions between the animals, HCP, and patients. These policies stated that all animal research must be approved by the institution's IACUC and, when research animals must be present in patient care areas, animal visits must be scheduled to minimize overlap with patient care activities. Policies also detailed how animals should be transported safely in the facility. For example, small animals should be caged and covered with drapes or opaque material. Other recommendations said that animals should only be transported in service elevators not utilized by patients. In cases where macaque nonhuman primates are research animals, one policy recommended that a bite and scratch kit and a copy of the CDC guideline on treatment of herpes $B$ virus accompany the animals. ${ }^{11}$ Policies reinforced the importance of comprehensive record keeping and appropriate waste disposal, noting that the principal investigator is ultimately responsible for these tasks. Policies varied on internal notification (eg, Infection Prevention and Control, Safety Compliance office).

\section{Personal Pet Visitation}

A total of 13 policies allowed personal pet visitation (Table 5). Some had no restrictions, while others stipulated that visitation could occur only under exceptional (compassionate) circumstances. Most of these institutions explicitly barred certain pets from visitation, including animals recently adopted from shelters, rodents, birds, reptiles, and amphibians. Some required that pets be at least 1-2 years of age and have resided in the patient's household for at least 6-12 months. While most institutions outlined prerequisites necessary to allow personal pet visitation, some only required permission from the nursing manager and attending physician. Some also required final approval by Infection Prevention and Control (IPC). Four institutions required veterinarian approval. 
table 5. Summary of Policy Requirements for Personal Pet Visitation

\begin{tabular}{lc}
\hline Situation & Institutions $(\mathrm{N}=23), \mathrm{No}(\%)$ \\
\hline Did not allow personal pets & $4 / 23(17)$ \\
No response or did not submit policy and procedure & $6 / 23(26)$ \\
Allowed personal pets & $13 / 23(54)$ \\
Allowed only dogs and cats & $6 / 13(46)$ \\
Allowed dogs only & $2 / 13(15)$ \\
Specified age ( $>1-2$ y/o) and duration of ownership (>6-12 mo) & $5 / 13(38)$ \\
Did not specify type of pets & $5 / 13(38)$ \\
Excluded many types of animals & $3 / 13(23)$ \\
Visitation prohibited for patients in isolation, ICU, or immunocompromised & $6 / 13(46)$ \\
Case-by-case determination & $8 / 13(44)$ \\
Allowed pets for extenuating circumstances & $6 / 13(46)$ \\
Specified duration of visitation $(1-2$ hr) & $5 / 13(38)$ \\
Required certification of pet's immunization status and good health & $5 / 13(38)$ \\
\hline
\end{tabular}

NOTE. ICU, intensive care unit.

TABLE 6. Allowable Uses of Animals in Healthcare (AHC) Facilities, Stratified by 4 Major Categories

\begin{tabular}{|c|c|c|c|c|c|c|c|c|c|c|c|c|}
\hline \multirow[b]{2}{*}{ Responses, No. (\%) } & \multicolumn{3}{|c|}{$\begin{array}{l}\text { Service Animals, } \\
\text { No. }(\%)\end{array}$} & \multicolumn{3}{|c|}{$\begin{array}{c}\text { Animal-Assisted Activities, } \\
\text { No. (\%) }\end{array}$} & \multicolumn{3}{|c|}{$\begin{array}{c}\text { Personal Pet Visitation, } \\
\text { No. }(\%)\end{array}$} & \multicolumn{3}{|c|}{$\begin{array}{c}\text { Research Animals, } \\
\text { No. }(\%)\end{array}$} \\
\hline & Yes & No & NA & Yes & No & NA & Yes & No & NA & Yes & No & NA \\
\hline US facilities 280 (83) & $67(95)$ & $8(3)$ & $5(2)$ & $249(89)$ & $24(9)$ & $7(3)$ & $113(40)$ & $158(57)$ & $9(3)$ & $99(35)$ & $155(56)$ & $26(9)$ \\
\hline Non-US facilities 24 (7) & $20(83)$ & $4(17)$ & 0 & $16(67)$ & $7(29)$ & $1(4)$ & $5(20)$ & $18(75)$ & $1(5)$ & $14(58)$ & $9(38)$ & $1(4)$ \\
\hline Unknown 33 (10) & $19(58)$ & $10(30)$ & $4(12)$ & $14(42)$ & $15(46)$ & $4(12)$ & $3(9)$ & $26(79)$ & $412)$ & $17(52)$ & $10(30)$ & $6(18)$ \\
\hline
\end{tabular}

NOTE. NA, not available.

\section{SURVEY OF SHEA MEMBERSHIP ON ANIMALS IN HEALTHCARE}

We conducted a survey of the SHEA Membership and SHEA Research Network from February through May 2013 and summarized responses from members' institutions about existing policies related to AHC.

\section{Survey Results}

A total of 337 SHEA members and members of the SHEA Research Network (21.7\% response of 1,550 members) responded to the survey regarding their institutions' policies for AHC (Table 6). The survey included questions regarding 4 situations in which animals would be encountered in the healthcare facility: animal-assisted activities (animal-assisted therapy programs/"pet therapy"), service animals, research animals, and personal pet visitation. The majority of respondents worked at acute care hospitals (93\%). Additional facilities included freestanding children's hospitals (4\%), freestanding clinics (1\%), and other facility types (2\%) such as specialty hospitals, research hospitals, and rehabilitation hospitals. The majority of responses were from university/teaching hospitals $(40 \%)$ or university/teaching-affiliated hospitals $(26 \%)$ and non-teaching hospitals $(24 \%)$. We received additional responses from Veterans Affairs and other government hospitals (4\%), free-standing pediatric hospitals (4\%), teaching non-university affiliated hospitals, and miscellaneous facilities (2\%). Most of the respondents were from US facilities (77\%) with representation from Canada (2\%), Latin America (3\%), Europe (3\%), Asia (3\%), Middle East (1\%) and other regions $(1 \%)$, while $10 \%$ did not identify their region. Of the 43 non-US respondents, only 24 were linked to institutionidentifying information; consequently, data from only these 24 institutions were analyzed.

Not all responding healthcare facilities with animal programs had formal policies. The following is the percentage of facilities that allowed animals but had no formal policy: animal-assisted activities (5.8\%, 18 of 306), service animals $(4.3 \%, 12$ of 279$)$, research animals $(8.5 \%, 11$ of 130$)$, personal pet visitation $(5.8 \%, 7$ of 121). Infection Prevention and Control frequently administered policies, with participation by human resources and legal services. Notably, 8 US facilities, including a Veteran's Hospital, reported that they did not allow service animals.

A total of 315 responses (93.5\%) addressed questions regarding the presence of animals in specific areas of the hospital. Almost all facilities restricted animals from the operating room, kitchen, central processing, and pharmacy (Table 7). Overall, 3 US facilities and 3 unidentified facilities had no restrictions; some cited the ADA as the reason. 
All facilities (279) that permitted animal-assisted activities allowed dogs, with $21 \%$ of facilities also allowing cats, $5 \%$ allowing miniature horses, and $2 \%$ allowing primates.

In summary, our review of institutional policies and of the survey results demonstrated substantial variation in practice around the issues related to AHC.

\section{Guidance Statement}

See Table 8 for summary of AHC classification and selected key recommendations from this document.

\section{ANIMAL-ASSISTED ACTIVITIES}

\section{Background}

The origins of animal-assisted activities remain obscure but seem to revolve around the "attachment theory" of Sigmund

TABLE 7. Areas of Healthcare Facility In Which Animals Were Prohibited (Responses $=315)$

\begin{tabular}{lc}
\hline Area in Healthcare Facility & $\begin{array}{c}\text { Percent of Facilities Prohibiting Animals } \\
\text { from Respective Areas, No. (\%) }\end{array}$ \\
\hline Intensive care unit & $230(73)$ \\
Operating room & $293(93)$ \\
Kitchen & $211(67)$ \\
Pharmacy & $280(89)$ \\
Step-down units & $123(39)$ \\
Recovery room & $271(86)$ \\
Central processing & $290(92)$ \\
\hline
\end{tabular}

Freud and may have initially been practiced in $19^{\text {th }}$ Century England. ${ }^{12}$ In 1919, dogs were used in therapeutic intervention with psychiatric patients at St. Elizabeth Hospital in Washington, DC. ${ }^{13}$ Since then, there have been increasing roles for AHC facilities. There are several categories of activities in which animals may be used with minor differences in definitions that often overlap:

1. Animal-assisted therapy, which includes animals as part of a specific treatment program.

2. Animal-assisted education (AAE), which includes goaldirected interventions designed to promote improvement in cognitive functioning of the person(s) involved and in which a specially trained $\operatorname{dog}$ and handler team is an integral part of an educational process.

3. Animal-assisted activities that include programs for visitation in hospitals that use specially trained animals and their handlers. Animal-assisted activities may include recreational and social purposes or goal-directed interventions in which an animal is involved as part of an organized treatment process, which may provide opportunities for motivational, educational, and/or recreational benefits to enhance a person's quality of life.

4. Animal visitation programs and "pet therapy" are interchangeable terms and are incorporated into the more general category of animal-assisted activities for the purposes of this document.

While individual institutions may have specific programs involving animals in the hospital, the vast majority of hospitals have "animal-assisted activities" as defined in this document.

TA вLE 8. Summary of Animals in Healthcare Classification and Selected Recommendations

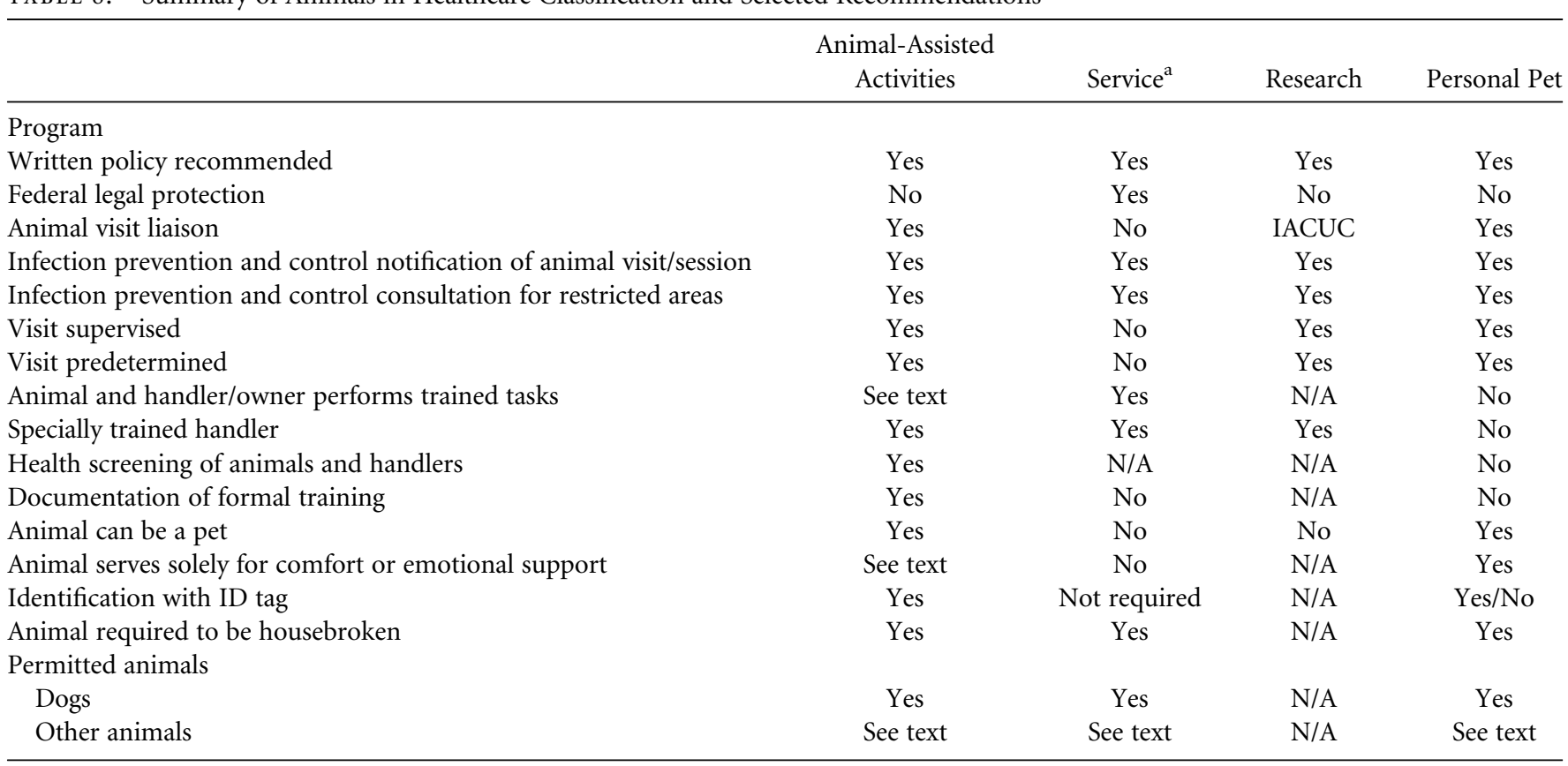

NOTE. IACUC, Institutional Animal Care and Use Committee.

${ }^{\mathrm{a}}$ Policy to reflect ADA and regulatory compliance. Inquiries limited by ADA to tasks performed for patient. 
Several published studies promote animal-assisted activities to improve psychological health, pain management, and lowering of blood pressure among patients and staff (Table 9). Most of these studies, though not scientifically rigorous, provide evidence of beneficial impacts on various patient populations from animal-assisted activities. In a review of "pet-facilitated therapy" as an aid to psychotherapy, Draper et $\mathrm{al}^{14}$ noted that although a literature review conducted in 1987 revealed more than 1,000 articles on the human-animal bond, only 6 controlled studies evaluating the therapeutic value of animalassisted activities had been reported as of 1983. These studies concluded that the benefits of animal-assisted activities relied heavily on anecdotal reports and the widespread attachment of persons with animals. In a critical appraisal of the literature from 1986 through 1997, Allen ${ }^{15}$ concluded that most reports describing the effects of human-canine interactions fell into the lowest category of scientific studies (ie, descriptive studies and expert opinion). Newer research, sometimes using controlled trials, has provided evidence that companion animals provide health benefits in the home setting. ${ }^{16}$ An increasing number of clinical trials are evaluating the benefits of animalassisted activities in the hospital (Table 9). Recently the American Heart Association (AHA) published a scientific statement regarding pet ownership and cardiovascular risk and concluded that pet ownership, particularly dog ownership, "is probably associated with" and "may have some causal role" in decreased cardiovascular disease risk. While not specifically reviewing animal-assisted activities, this endorsement by a major professional organization is noteworthy.

\section{Differences Between Animal-Assisted Activities Animals and Service Animals}

Animal-assisted activities animals and their handlers are trained to provide specific human populations with appropriate contact with animals. ${ }^{17}$ They are usually personal pets of the handlers and accompany their handlers to the sites they visit, although animal-assisted activities animals may also reside at a facility. Animal-assisted activities animals must meet specific criteria for health, grooming, and behavior, and their access can be restricted at the discretion of the facility. Animal-assisted activities animals are not service animals. Federal law, which protects the rights of qualified persons with disabilities in terms of service animals, has no provision for animal-assisted activities animals.

\section{Guidance (Animal-Assisted Activities)}

I. Overview of management of an animal-assisted activities program within a healthcare facility.

A. Facilities should develop a written policy for animalassisted activities.

B. An animal-assisted activities visit liaison should be designated to provide support and facilitate animal-assisted activities visits. Often these visits are managed by the facility's Volunteer Office or Department.
C. Only dogs should be used (ie, exclude cats and other animals). Cats should be excluded because they cannot be trained to reliably provide safe interactions with patients in the healthcare setting.

D. Animals and handlers should be formally trained and evaluated. Facilities should consider use of certification by organizations that provide relevant formal training programs (eg, Pet Partners, Therapy Dogs Incorporated, Therapy Dogs International). Alternatively, facilities should designate responsibility for the program elements to an internal department (eg, volunteer department) to verify all elements (see section III).

E. Animals and animal handlers should be screened prior to being accepted into a facility animal-assisted activities program (see section II)

F. The IPC should be consulted regarding which locations are appropriate for animals interacting with patients.

G. All clinical staff should be educated about the animalassisted activities program, its governance, and its policies.

II. Training and management of animal-assisted activities handlers. Facilities should do the following:

A. Ensure that animal-assisted activities handlers have been informed of the facility's IPC and human resource policies (similar to volunteers) and have signed an agreement to comply with these policies.

B. Confirm that animal-assisted activities handlers have been offered all immunizations recommended for healthcare providers (HCP) within that facility (eg, measles, mumps, and rubella, varicella, pertussis, influenza). If immunization is required of HCP, it should be required for animal-assisted activities handlers.

C. Require the animal-assisted activities handler to escort the animal to the destination as arranged by the facility's animalassisted activities liaison and following hospital policy.

D. Instruct the animal-assisted activities handler to restrict contact of his or her animal to the patient(s) being visited and to avoid casual contact of their animal with other patients, staff or the public.

E. Limit visits to 1 animal per handler.

F. Require that every animal-assisted activities handler participate in a formal training program and provide a certificate confirming the training, which includes modules on the following:

1. Zoonotic diseases

2. Training on standard precautions including hand hygiene before and after patient contact

3. Proper cleaning and disinfection of surfaces contaminated by animal waste (urine or feces)

4. Proper disposal of animal waste

5. Visual inspection for ectoparasites

6. Reading of an animal's body language to identify signs of physical discomfort, stress, fear, or aggression

7. Identification of appropriate contacts in the event of an accident or injury 
TAвLE 9. Review of Selected References on Animal-Assisted Activities

\begin{tabular}{lll}
\hline Author, Year, (Ref. No.) & Type & Methodology \\
\hline Abate SV, 2011 (71) & Hospitalized heart- & Subjects were provided the opportunity to \\
& failure patients & participate in canine-assisted \\
& ambulation (walking with a therapy \\
& dog). Case subjects were compared with \\
& a historical population of \\
& 537 controls.
\end{tabular}

Findings

Distance ambulated increased from 120.2 steps in a randomly selected, stratified historical sample to 235.07 in the canine-assisted ambulation study sample $(P<.0001)$. Subjects unanimously agreed that they enjoyed canine-assisted ambulation and would like to participate in canineassisted ambulation again.

Banks MR, 2002 (72) Long-term care

Barak Y, 2001 (73)

Psychiatric ward

Barker SB, 2003 (74)

Barker SB, 1998 (75)

Beck CE, 2012 (76)

Outpatient veterans

Brodie SJ, 1999 (77)

Chu CI, 2009 (78)

Cole KM, 2007 (79)

Hospitalized heartfailure patients

Edwards NE, 2002 (80) Alzheimer's disease therapy (ECT)

Psychiatric patients
Randomized clinical trial, three groups of 15 patients (no animal-assisted therapy; animal-assisted therapy once/week; animal-assisted therapy $3 \mathrm{x} /$ week); pre-post assessment

Randomized clinical trial of 20 patients, 10 with and 10 without animal-assisted therapy

Fear in electroconvulsive

Taiwanese inpatients with schizophrenia

30 participants were randomly assigned to either a weekly animal-assisted activities program for 2 mo (treatment) or no animal contact (control).

3-group randomized repeated-measures experimental design was used in 76 adults: group 1 received a 12 -minute visit from a volunteer with a therapy dog; group 2, a 12-min visit from a volunteer; and the control group, usual care.

Evaluated effects of fish aquariums on nutritional intake in individuals with Alzheimer's disease in 62 patients.
Residents volunteering for the study had a strong life-history of emotional intimacy with pets.

AAA significantly reduced loneliness scores in comparison with the no animal-assisted therapy group.

Improvement was noted in both groups compared with baseline scores and were significantly more positive for the AAA group on both Total Social Adaptive Functioning Evaluation score and on the Social Functions subscale.

Animal-assisted therapy reduced fear and anxiety but had no demonstrated effect on depression.

Reductions in anxiety scores were found after the animal-assisted therapy session for patients with psychotic disorders, mood disorders, and other disorders. No significant differences found in reduction of anxiety.

Differences were not found between the groups on most measures; subjective reports of satisfaction with AAA.

Potential benefits of pet therapy are considerable and nurses may assume an active role in advocating ward pet or pet-visiting schemes.

The treatment group showed significant improvement on all measures except for social support and negative psychiatric symptoms.

Animal-assisted therapy improved cardiopulmonary pressures, neurohormone levels, and anxiety in patients hospitalized with heart failure.

Nutritional intake increased significantly when the aquariums were introduced. 
т AвLE 9. Continued

\begin{tabular}{lll}
\hline Author, Year, (Ref. No.) & Type & Methodology \\
\hline $\begin{array}{l}\text { Edwards NE, } 2014(81) \\
\text { Aquaria in long-term } \\
\text { care dementia }\end{array}$ & $\begin{array}{c}\text { Pre-post test design-3 units, } 71 \\
\text { individuals with dementia and } 71 \\
\text { professional staff. }\end{array}$ \\
Jorgenson J, $1997(82)$ & $\begin{array}{l}\text { Review } \\
\text { Kamioka H, } 2014(83)\end{array}$ & \\
& & $\begin{array}{c}\text { Review of randomized controlled trials } \\
\text { from } 1990 \text { to October } 31,2012 ; \\
11 / 57 \text { studies met criteria for analysis }\end{array}$
\end{tabular}

Findings

Residents' behaviors improved along four domains: uncooperative, irrational, sleep, and inappropriate behaviors.

Benefits of the animal-human bond may include decreased blood pressure, heart rates, and stress levels, as well as increases in emotional well-being and social interaction.

Randomized clinical trials relatively low quality and heterogeneity precluded meta-analysis. In a study environment limited to people who like animals, animal-assisted therapy may be an effective treatment for mental and behavioral disorders.

Levine GN,2013 (84)

Marcus DA 2013 (85)

Moretti F, 2011 (86)

Nepps P, 2014 (87)

Nordgren L, 2014 (88)

Dementia patients

Sobo EJ, 2006 (89)

Swall A, 2014 (90)

Pediatric hospital

Alzheimer's disease

\section{American Heart Association scientific statement \\ Literature review and rationale \\ Nursing home patients with dementia, depression and psychosis.}

Community hospital mental health unit

Review of 36 studies

Review of 6 studies

Mini-Mental State Examination (MMSE) and Geriatric Depression Scale (GDS) administered to 10 animal-assisted activities patients and 11 controls before and after a 6-week pet therapy intervention.

218 patients on mental health unit of a community hospital with an existing, complementary animal-assisted activities program. Half of the patients participated in a 1-h session of animalassisted activities and comparison group in a 1-h stress management program.

6-month study of 33 residents of Swedish nursing homes with dementia (20 in the intervention group; 13 in the control group). Assessment of the effects of a dog-assisted intervention on behavioral and psychological symptoms. The intervention comprised ten sessions (45-60 min, 1-2 $\times$ /week).

Pre-post mixed-methods survey in pediatric hospital (25 patients)

Video recorded sessions were conducted for each visit of the dog and its handler to a person with Alzheimer's disease.
Review
Pet (particularly dogs) ownership may have some causal role in reducing cardiovascular disease risk.

Dog therapy visits reduced pain and pain-related symptoms.

Improved depressive symptoms and cognitive function in residents of long-term care facilities with mental illness.

Significant decreases $(P<.05)$ in depression, anxiety, pain, and pulse after animal-assisted activities program, compared to those in the more traditional stress management group.

Some positive tendencies were observed. Dog-assisted intervention may provide an alternative or a complement to pharmacological treatments to reduce behavioral symptoms in people with dementia, but its value and place in care require further evaluation.

Pet visitation reduced perceived pain.

Time spent with the dog shows the person recounting memories and feelings, and enables an opportunity to reach the person on a cognitive level.

Animals can promote feelings of selfworth, help offset loneliness, reduce anxiety, provide contact, comfort, security, and the feeling of being needed. 
G. Require that a handler use particular care in directing the visit to prevent patients from touching the animal in inappropriate body sites (eg, mouth, nose, perianal region) or handling the animal in a manner that might increase the likelihood of frightening or harming the animal or the animal accidentally or intentionally harming the patient.

H. Restrict visiting sessions to a maximum of 1 hour to reduce the risk of adverse events associated with animal fatigue.

1. Handlers must observe the animal for signs of fatigue, stress, thirst, overheating, or urges to urinate or defecate.

a. If taking a short break (or taking the animal outside to relieve it) does not ease the animal's signs of discomfort, then the session should be terminated for that day.

2. Handlers must comply with facility-defined restrictions for patient visits and be familiar with facility-specific signage regarding restricted areas or rooms.

I. Require that all animal handlers observe standard occupational health practices. Specifically, they should self-screen for symptoms of communicable disease and refrain from providing animal-assisted activities services while ill. Such symptoms include, but are not limited to the following:

1. New or worsening respiratory symptoms (ie, cough, sneezing, nasal discharge)

2. Fever (temperature $>38^{\circ} \mathrm{C}$ )

3. Diarrhea or vomiting

4. Conjunctivitis

5. Rash or non-intact skin on face or hands

J. Require that handlers keep control of the animal at all times while on the premises, including the following:

1. Keeping a dog leashed at all times unless transported within the facility by a carrier (as may be the case with smaller breeds).

2. Refraining from using cell phones or participating in other activities that may divert his/her attention away from the animal.

K. Require all handlers to manage their animal as follows:

1. Approach patients from the side that is free of any invasive devices (eg, intravenous catheters) and prevent the animal from having contact with any catheter insertion sites, medical devices, breaks in the skin, bandage materials, or other compromised body site.

2. Before entering an elevator with an animal, ask the other passengers for permission, and do not enter if any passenger expresses reluctance or appears apprehensive.

3. Require that everyone who wishes to touch the animal practice hand hygiene before and after contact.

4. Do not permit a patient to eat or drink while interacting with the animal.

5. Restrict the animal from patient lavatories.

6. In the case of an animal's urinary or fecal accident, immediately terminate the visit and take appropriate measures to prevent recurrence during future visits. a. If submissive urination was involved, this will require suspending the animal's visiting privileges, having the handler address the underlying cause, and then formally reevaluating the animal's suitability before visiting privileges are restored.

b. If repeated incidents of this nature occur, permanently withdraw the animal's visiting privileges.

c. In the case of vomiting or diarrhea, terminate the visit immediately and withdraw the animal from visitation for a minimum of 1 week.

7. Report any scratches, bites, or any other inappropriate animal behavior to healthcare staff immediately so that wounds can be cleaned and treated promptly. Report any injuries to the animal-assisted activities liaison as soon as possible and to public health or animal control authorities, as required by local laws.

a. The visit should be immediately terminated after any bite or scratch.

b. In the case of bites, intentional scratches, or other serious, inappropriate behavior, permanently withdraw the animal's visiting privileges.

c. In the case of accidental scratches, consider the circumstances that contributed to the injury and take appropriate measures to prevent similar injuries from occurring in the future. If measures cannot be taken to reduce the risk of recurrence, then visitation privileges should be withdrawn.

d. If it is determined that the handler's behavior was instrumental in the incident, then the handler's visitation privileges should be terminated until the animal-assisted activities program manager has addressed the situation.

e. Report any inappropriate patient behavior (eg, inappropriate handling, refusal to follow instructions) to the animal visit liaison.

L. Facilities should maintain a log of all animal-assisted activities visits that includes rooms and persons visited for potential contact tracing.

III. Requirements of acceptable animals for animal-assisted activities programs

A. Allow only domestic companion dogs to serve as animalassisted activities animals. Cats are not included in the recommendation due to concerns for increased potential allergenicity, potential increased risk of bites and scratches, and lack of data demonstrating advantages over dogs.

1. Allow only adult dogs (ie, dogs of at least 1 year but ideally at least 2 years of age, the age of social maturity).

2. Deny the entry of dogs directly from an animal shelter or similar facility.

3. Require that dogs be in a permanent home for at least 6 months prior to enrolling in the program.

4. Admit a dog only if it is a member of a formal animalassisted activities program and is present exclusively for the purposes of animal-assisted activities. 
B. Require that every dog pass a temperament evaluation specifically designed to evaluate it under conditions that might be encountered when in the healthcare facility. Such an evaluation should be performed by a designated evaluator.

1. Typically, this evaluation will assess, among other factors, reactions toward strangers, loud and/or novel stimuli, angry voices and potentially threatening gestures, being crowded, being patted in a vigorous or clumsy manner, reaction to a restraining hug, interactions with other animals, and the ability to obey handler's commands.

C. Require all evaluators (either at facility or at the formal certification program) to successfully complete a course or certification process in evaluating temperament and to have experience in assessing animal behavior and level of training.

1. Require all evaluators to have experience with animal visiting programs or, at the very least, appreciate the types of challenges that animals may encounter in the healthcare environment (eg, startling noises, crowding, rough handling).

2. If several animals need to be evaluated for behaviors other than reactions to other animals, require that the temperament evaluator assess each animal separately, rather than assessing several animals simultaneously.

D. Recommend that animal-handler teams be observed by an animal-assisted activities program liaison at least once in a healthcare setting before being granted final approval to visit.

E. Recommend that each animal be reevaluated at least every 3 years.

F. Require that any animal be formally reevaluated before returning to animal-assisted activities after an absence of $>3$ months.

G. Require that a handler suspend visits and have his or her animal formally reevaluated whenever he or she notices or is apprised (either directly or through the animal visit liaison) that the animal has demonstrated any of the following:

1. A negative behavioral change since the time it was last temperament tested

2. Aggressive behavior outside the healthcare setting

3. Fearful behavior during visitations

4. Loss of sight or hearing and, consequently, an overt inclination to startle and react in an adverse manner

H. Health screening of animals

1. Basic requirements for all animals

a. Require that dogs be vaccinated against rabies as dictated by local laws and vaccine label recommendations. Serologic testing for rabies antibody concentration should not be used as a substitute for appropriate vaccination.

b. Exclude animals with known or suspected communicable diseases. c. Animals with other concerning medical conditions should be excluded from visitation until clinically normal (or the condition is managed such that the veterinarian feels that it poses no increased risk to patients) and have received a written veterinary health clearance. Examples include episodes of vomiting or diarrhea; urinary or fecal incontinence; episodes of sneezing or coughing of unknown or suspected infectious origin; animals currently on treatment with non-topical antimicrobials or with any immunosuppressive medications; infestation by fleas, ticks, or other ectoparasites; open wounds; ear infections; skin infections or "hot spots" (ie, superficial folliculitis or pyoderma); and orthopedic or other conditions that, in the opinion of the animal's veterinarian, could result in pain or distress to the animal during handling and/or when maneuvering within the facility.

d. Exclude animals demonstrating signs of heat (estrus) during this time period.

2. Scheduled health screening of animal-assisted activities animals

i. Require that every animal receive a health evaluation by a licensed veterinarian at least once (optimally, twice) per year.

1. Defer to the animal's veterinarian regarding an appropriate flea, tick, and enteric parasite control program, which should be designed to take into account the risks of the animal acquiring these parasites specific to its geographic location and living conditions.

2. Routine screening for specific, potentially zoonotic microorganisms, including group A streptococci, Clostridium difficile, VRE, and MRSA, is not recommended.

ii. Special testing may be indicated in situations where the animal has physically interacted with a known human carrier, either in the hospital or in the community, or when epidemiologic evidence suggests that the animal might be involved in transmission. Testing should be performed by the animal's veterinarian in conjunction with appropriate infection prevention and control and veterinary infectious disease personnel, if required.

iii. Special testing may be indicated if the animal-assisted activities animal is epidemiologically linked to an outbreak of infectious disease known to have zoonotic transmission potential. Suspension of visitation pending results is recommended in these situations.

3. Dietary guidelines for all animals

a. Exclude any animal that has been fed within the past 90 days any raw or dehydrated (but otherwise raw) foods, chews, or treats of animal origin, excluding those that are high-pressure pasteurized or $\gamma$ irradiated.

IV. Preparing animals for visits:

1. Require that every handler do the following:

i. Brush or comb the animal's hair coat before a visit to remove as much loose hair, dander, and other debris as possible. 
ii. Keep the animal's nails short and free of sharp edges.

iii. If the animal is malodorous or visibly soiled, bathe it with a mild, unscented (if possible), hypoallergenic shampoo and allow the animal's coat to dry before leaving for the healthcare facility.

iv. Visually inspect the animal for fleas and ticks.

v. Clean the animal carrier.

vi. Maintain animal leashes, harnesses, and collars visibly clean and odor-free.

vii. Use only leashes that are non-retractable and 1.3 to $2 \mathrm{~m}$ (4 to 6 feet) or less in length.

viii. Not use choke chains or prong collars, which may trap and injure patients' fingers.

ix. Make an animal belonging to an animal-assisted activities program identifiable with a clean scarf, collar, harness or leash, tag or other special identifier readily recognizable by staff.

x. Provide a dog with an opportunity to urinate and defecate immediately before entering the healthcare facility. Dispose of any feces according to the policy of the healthcare facility and practice hand hygiene immediately afterward.

V. Managing appropriate contact between animals and people during visits

A. Obtain oral or written consent from the patient or his or her agent for the visit and preferably from the attending physician as well. Consider documenting consent in the patient's medical record.

B. The handler should notify caregiver (eg, nurse or physician) of the animal visitation.

C. The handler should be required to obtain oral permission from other individuals in the room (or their agents) before entering for visitation.

D. All visiting animals should be restricted from entering the following clinical areas at all times, in addition to nonclinical areas outlined below in Service Animals section V.E.2.:

1. Intensive care units; isolation rooms; neonatal and newborn nurseries; areas of patient treatment where the nature of the treatment (eg, resulting in pain for the patient) may cause the animal distress; and other areas identified specifically by the healthcare facility (eg, rooms of immunocompromised patients).

E. Require the handler to prevent the animal from coming into contact with sites of invasive devices, open or bandaged wounds, surgical incisions, or other breaches in the skin, or medical equipment.

F. If the patient or agent requests that an animal be placed on the bed, require that the handler do the following:

1. Check for visible soiling of bed linens first.

2. Place a disposable, impermeable barrier between the animal and the bed; throw the barrier away after each animal visit.

3. If a disposable barrier is not available, a pillowcase, towel, or extra bed sheet can be used. Place such an item in the laundry immediately after use and never use it for multiple patients.

G. Instruct the handler to discourage patients and HCP from shaking the animal's paw. If the dog is trained to shake hands with a patient and this contact is allowed by facility, ensure that the patient performs hand hygiene before and after shaking the animal's paw.

$\mathrm{H}$. Require the handler to prevent the animal from licking patients and HCP.

I. Prohibit feeding of treats to animals by HCP; however, if the act is believed to have a significant therapeutic benefit for a particular patient, then require that the handler:

1. Ensure that the animal has been trained to take treats gently.

2. Provide the patient with appropriate treats to give, avoiding unsterilized bones, rawhides and pig ears, and other dehydrated and unsterilized foods or chews of animal origin.

3. Ensure that the patient practices hand hygiene before and after presenting the treat to the animal.

4. Instruct the patient to present the treat with a flattened palm.

\section{Contact tracing}

A. The facility should develop a system of contact tracing that at a minimum requires animal handlers to sign in when visiting and ideally provides a permanent record of areas and/or room numbers where the animal has interacted with patients.

VII. Environmental cleaning

A. Practice routine cleaning and disinfection of environmental surfaces after visits. Clean and disinfect all areas (eg, floors, chairs) with an EPA-registered hospital disinfectant.

B. It is recommended that clean additional bed sheet be used to cover the bed if the animal has contact with surface of the bed, and this should be removed and laundered after the animal visit. If a separate sheet is not used, replace any bedding that might be contaminated.

\section{SERVICE ANIMALS}

\section{Background}

The Americans with Disabilities Act (ADA) is a US Federal law that was passed in 1990 and has been subsequently updated. ${ }^{9}$ This law established certain legal rights for persons with service animals and defined the minimum access required by law. Under the ADA, "service animals" are defined as "dogs that are individually trained to do work or perform tasks for people with disabilities." ${ }^{\prime 9}$ The ADA provides a limited exception for miniature horses if these animals otherwise satisfy the definition of a "service animal," are housebroken, and do not create safety concerns. Legal protection extends only to individuals who are disabled, as defined under the ADA, not all patients with medical or psychological conditions. While a full exploration of what constitutes a "disability" is beyond the scope of this review, disability is generally defined by the 
statute as (1) a physical or mental impairment that substantially limits one or more major life activities, (2) a record of such an impairment, or (3) being regarded as having such an impairment.

Guidance provided by the Department of Justice makes clear that service animals under the ADA are "working animals" and not pets, and they are trained to perform specific duties or tasks. If the individual has a "disability" as defined by the statute, service animals may include "alert" animals (ie, an animal trained to alert a person about to have a seizure and to take actions to protect that individual during the seizure) and animals trained to assist individuals with post-traumatic distress syndrome (eg, calming that person during an anxiety attack); however, a dog whose sole function is comfort or emotional support is not considered a service dog. For more information, see the guidelines provided by the Civil Rights Division of the US Department of Justice. ${ }^{18}$ Federal guidelines limit the inquiries that staff may make when it is not obvious that the person is disabled and is using a service dog, as defined by the ADA. Staff may not require documentation about the person's disability or the animal's training but may ask: (1) "Is the dog a service animal required because of a disability?" and (2) "What work or task is the dog trained to perform?" While restriction of access to service animals is permitted in situations where public health may be compromised, allergies or fear of dogs by staff or other patients generally are not acceptable reasons for denying access. The facility is required to make adjustments as needed to accommodate the animal.

\section{Guidance}

I. Each healthcare facility should have a policy regarding the admittance of service animals into the facility.

A. The policy allowing service animals into the facility should be compliant with the Federal Americans with Disabilities Act (ADA), any other applicable state and local regulations (note that federal law pre-empts more restrictive state or local regulations)., ${ }^{9,18}$

B. A policy regarding the entrance of service animals into the facility should include the following information:

1. A clear definition of "Service Animals" that should be consistent with the ADA (see Background of Section III for definitions). The facility is not required to permit animals in training to become service animals to enter the facility, but may choose to do so, reserving the right to exclude such animals at its discretion.

2. A statement that only dogs and miniature horses are recognized as Service Animals under federal law.

3. A statement that service animals are NOT pets and should NOT be approached, bothered, or petted.

4. A statement that the care of the service animal is the responsibility of the patient or his or her designated visitor (ie, it is not the responsibility of the healthcare facility's personnel). If the patient is unable to arrange for the care of the service animal while in the facility, the animal should not be permitted to remain.

5. Notification of the IPC that an inpatient has a service animal, followed by discussion with the patient to make sure the service animal complies with institutional policies.

6. A requirement that service animals be housebroken.

II. Persons with disabilities may be requested but not required to have their service animal wear an identification tag (eg, collar, tag, etc.) that identifies them as a service animal to aid HCP in distinguishing service animals from pets.

III. Situations sometimes arise in which a patient or visitor claims that a dog is a service animal (and the animal may be wearing a vest or other item identifying it as a service animal), but the animal's behavior suggests that the animals is not a service animal (eg, the animal appears undisciplined, repeatedly approaches other visitors or patients for attention, does not display any behavior that is assisting its master, etc.). Healthcare providers or staff may ask the patient to describe what work/tasks the dog performs for the patient, but may not ask for a "certification" or "papers." There are no formal certification or registration programs for service animals and certificates and paperwork can be readily purchased for any pet from various 'agencies.' The facility's policy should note that the term "Service Animal," as defined under the ADA, does not include dogs used for the provision of emotional support, well-being, comfort, or companionship. It may be helpful to quote directly from the ADA regulations that make this distinction.

IV. Situations in which a service animal may be excluded from the healthcare facility include the following:

A. The animal exhibits aggressive behavior such as snarling, biting, scratching, or teeth baring.

B. The animal is excessively noisy (eg, howling, crying, or whining).

C. The animal is unable to properly contain bodily excretions (eg, the animal is not housebroken, or has vomiting or diarrhea).

D. If the facility's personnel reasonably believes that a service animal is infectious or ill (see animal-assisted activities section III.H.1.b and c for examples), the animal should not be allowed to remain with the person with a disability until the animal is evaluated by a veterinarian and he/she provides written certification, acceptable to the healthcare facility, that the service animal does not pose an increased risk to patients or staff.

E. The policy should include a list of locations from which service animals are prohibited and reasons for that exclusion.

1. Where exclusion is based solely on risk to the service animal, the patient should be consulted.

2. When the service animal is restricted from accompanying the patient, reasonable accommodation should be made for the person with disability to function without the 
service animal. Areas from which service animals should be prohibited include the following:

i. Invasive procedure areas where sterility is required, including but not limited to the operating rooms, recovery rooms, cardiac catheterization suites, and endoscopy suites.

ii. Patient units where a patient is immunocompromised or deemed at particularly high risk for infection, or in isolation for respiratory (droplet or airborne) contact, or compromised host precautions, unless in a particular circumstance a service animal does not pose a direct threat and the presence of the service animal would not require a fundamental alteration in the hospitals' policies, practices, or procedures.

iii. Food and medication preparation areas where appropriate hygiene is required, including but not limited to kitchen, infant formula preparation room, and central and satellite pharmacies.

iv. Areas where the service animal or equipment may be harmed by exposure (eg, metal is not allowed in a magnetic resonance imaging (MRI) room, and a dog may have metal on a collar or in a surgical implant), after consultation with the patient or his/her authorized representative. When there is potential harm to the service animal (eg, animal present in room during radiation therapy), the patient should be advised of the potential harm and assumes full responsibility for any harm to the service animal.

F. Legal counsel should be consulted prior to exclusion of a service animal from a healthcare facility.

G. Any consideration of restricting or removing a service animal should be done with careful discussion with the patient (and/or his or her designee) to achieve consensus and provide an understanding of the concerns.

$\mathrm{V}$. The policy should include the following regarding the health of the service animal:

A. The person with a disability (or his or her designee) is responsible for ensuring the health and care of the service animal.

B. Visiting or residing in a healthcare facility likely increases the risk of the animal acquiring certain pathogens. The healthcare facility assumes no liability for costs associated with a hospital-associated infection in the service animal.

VI. The policy should address a service animal's accompanying a healthcare facility visitor to a patient room and should include the following:

A. Persons with disabilities who are accompanied by service animals are allowed to visit patients as long as visitation occurs in accordance with the facility's service animal policy and the facility's "visiting hours and regulations."

B. Service animals are not allowed to visit other patients' rooms, the dining rooms, or other public areas of the facility unless accompanied by the person with a disability.

C. When a person with a disability visits a patient's room, he or she should check with the patient's primary care nurse before visiting to assure that no patient in the room has allergies to the service animal or bears other significant medical risks that would contraindicate being near an animal. If another patient in the room has an allergy, other significant medical risk from exposure to an animal, or is fearful of the animal, other arrangements for visiting must be made (eg, visit in day room or waiting room).

VII. The policy should address the following for a service animals belonging to patients:

A. When patients with a service animal are assigned to a semiprivate room, the roommate must be screened for clinically significant allergies to the service animal and, if such a condition is present, either the patient with the disability or the patient with animal allergies must be moved to another room. Similarly, the patient or roommate must be moved if the roommate is fearful or otherwise disturbed by the presence of the animal.

B. IPC should be notified when patients are admitted with service animals.

C. The patient must be able to make arrangements to have the service animal fed, exercised, and toileted, without the involvement of HCP.

VIII. The policy should specifically address the use of a miniature horse trained to do work or perform tasks for a person with a disability. Miniature horses generally range in height between 24 inches and 34 inches measured to the shoulders and generally weigh between 70 and 100 pounds. Factors used to assess whether a miniature horse should be permitted in the healthcare facility include the following:

A. Whether the miniature horse is housebroken.

B. Whether the miniature horse is under the owner's control.

C. Whether the facility can accommodate the miniature horse's type, size, and weight.

D. Whether the miniature horse's presence will not compromise legitimate safety requirements necessary for safe operation of the facility.

E. The policy should clearly state who is assigned to enforce the policy (eg, legal).

\section{RESEARCH ANIMALS}

\section{Background}

Health-science centers are dedicated to advancing human health through basic as well as clinical and translational research. Biomedical research often requires the application of sophisticated equipment and clinical techniques for research animals. Because of logistics and expense, some equipment items and facilities may not be able to be dedicated solely for animal use; thus, research animals may need to be studied in human healthcare institutions using equipment and facilities that are also used for humans. Similarly, on occasion, zoos or veterinary facilities may appeal for use of human healthcare facilities to diagnose or treat sick or injured animals. To accommodate these situations, when applicable, acute care 
hospitals should have comprehensive policies and procedures in place to ensure patient and public safety while enabling safe, effective, and efficient evaluation and treatment of animals.

As healthcare facilities develop infection prevention policies and procedures to evaluate and treat research animals, they should focus on 2 factors: (1) animals can serve as a reservoir and vehicle for potentially infectious pathogens, and (2) human safety must take priority over research project goals. Our focus is on transmission of infectious agents (see below); however, it should be noted that some animal species may pose additional threat, such as physical injury from large animals or envenomation.

Potential pathogens can be transmitted from research animals-to-humans. Accredited healthcare research centers expend great effort to ensure research animal well-being and to minimize the likelihood that research animals harbor human pathogens. However, risk cannot be eliminated because many potential pathogens are part of the normal microbiota of animals. This brief guidance statement is not meant to catalog all of the potential infectious agents that can be transmitted from animals to humans. A few examples are noted below to illustrate the range of pathogens and routes of inoculation.

1. Direct inoculation via percutaneous or mucosal membrane exposure

A large number of pathogens can be carried in the blood and body fluids of research and veterinary animals and have on occasion been spread to laboratory workers or healthcare providers. Examples include Streptobacillus moniliformis (rat bite fever) resulting from the bite or scratch of laboratory rodents; ${ }^{19}$ herpes B virus encephalitis, transmitted by the bite of non-human primates; ${ }^{20}$ skin and soft tissue infection due to Pasteurella multocida from cat bites and scratches and dog bites; ${ }^{21}$ and infection due to lymphocytic choriomeningitis virus, associated with exposures to laboratory rodents. ${ }^{22}$

2. Inhalation

Coxiella burnetii ( $\mathrm{Q}$ fever) and Chlamydophila psittaci (psittacosis) are examples of pathogens that have been spread from laboratory animals-to-humans. ${ }^{23,24}$

3. Direct contact

Zoophilic dermatophytes (Microsporum canis, Trichophyton mentagrophytes) may potentially be spread from infected mammals to humans. ${ }^{25}$ Similarly, MRSA has been noted to colonize various domestic animal species.

4. Fecal-oral

A large number of pathogens may be carried subclinically in the gastrointestinal tracts of laboratory animals and can potentially be transmitted via the fecal-oral route. Examples include Salmonella ssp. (many animal species), Campylobacter ssp. (mammals, birds, reptiles) and Cryptosporidium ssp. (mammals, reptiles, primates).

5. Indirect transmission via vectors

Occasionally, laboratory animals may harbor ectoparasites (eg, fleas), and these may serve as vectors for transmission of various pathogens to human laboratory personnel or HCP.

To minimize the risk of transmission of pathogens to humans, institutions should formulate thorough procedures to safely conduct diagnostic and therapeutic procedures on research animals and animals from veterinary or zoologic sources.

\section{Guidance}

I. Review and approval

A. Before any research animal is evaluated in a human healthcare facility, the principal investigator should submit a detailed protocol that is reviewed and approved by the facility's responsible individuals or committees including the following:

1. IACUC

2. Radiation safety committee (if procedures utilize radiation or radioisotopes), infection prevention and control department, and the involved clinical departments (radiology, surgical services, etc.).

B. External advice should be sought as necessary to ensure that there is adequate expertise to identify risks and develop preventive measures.

C. The review and approval process should be supervised and monitored by a responsible entity, such as the institutional Comparative Medicine Department or Infection Control Department. In some circumstances, animals with active or uncontrolled infections may need to be specifically excluded from entering the facility (eg, open/draining wounds, diarrheal illness).

1. In addition to approving proposed procedures involving animals, the detailed protocol should address all relevant issues, including the following:

a. When the procedure may be performed

b. Where the procedure is to be performed

c. What personnel will be involved

d. What personal protective equipment is required

e. What cleaning and disinfection practices will be required

f. What route(s) will be used to transport animals to and from the clinical area

g. Who is responsible for transporting the animal to the procedure area

h. Who is responsible for care and maintenance of the animal

II. Scheduling

A. After a protocol is approved, the investigator should work with the appropriate clinical area to schedule procedures to minimize the potential for animal contact with patients or the public.

B. Procedures on animals should be scheduled after normal clinical hours (ie, nights, weekends, and holidays) at a time when facilities and equipment are not being utilized for patient care. 
C. The researcher must remain sensitive to the vagaries of clinical practice and must understand that clinical situations may arise that preclude the use of facilities for research animals even though the animal procedure had been scheduled.

D. Effective communication between the researcher and the clinical area manager is crucial.

III. Transportation

A. Animals must be transported to and from clinical areas in an enclosed, escape-proof container that is opaque or concealed. If the animal is too large for a carrier (eg, pigs), it should be anesthetized prior to entry to the healthcare facility, restrained, and covered by a blanket.

B. Transportation routes should be utilized that minimize the potential for contact with patients or the public.

C. Service elevators should be used whenever possible.

D. Animals and patients or patient-care items should not be transported on the same elevator.

IV. Procedures in patient care areas

A. Animals should be prepared prior to transport as indicated for the procedure (eg, hair removal, skin preparation, bladder catheterization, intravenous access).

B. Whenever possible, procedures should be done in the housing area or otherwise away from human clinical areas.

C. All mobile equipment and materials not needed for the animal procedure should be removed from the procedure room.

D. Consider covering the examination table with leak-proof plastic sheeting that is lined with absorbent material.

E. Doors to the procedure room should be closed, and a "Do Not Enter" sign should be posted.

F. Appropriate personal protective equipment should be utilized by personnel.

V. Equipment

A. Use of disposable equipment is desirable.

B. When using equipment that is also used on patients, only equipment that has an established protocol for proper and effective cleaning and can be effectively disinfected or sterilized (as appropriate) should be used.

C. Medical or surgical instruments, especially those invasive instruments that are difficult to clean (eg, endoscopes) that are used on animals should be reserved for future use only on animals.

D. Only disposable or dedicated equipment should be used if there is any chance such equipment may be contaminated with prions (eg, bovine spongiform encephalopathy or scrapie).

VI. Cleanup/waste disposal

A. At the conclusion of the procedure, the room must be thoroughly cleaned with an EPA registered disinfectant that is appropriate for the pathogen risks posed by the animals.

B. Patients are not allowed entry until the room has been cleaned and disinfected.

C. If appropriate, a portable HEPA unit should be placed in the room and run until the next work day to reduce airborne particulate allergens.
D. All waste generated during the study should be considered potentially biohazardous and be disposed as regulated waste.

VII. Veterinary procedures

A. Whenever possible, animals should be treated in facilities specialized for animal care; however, the expense of specialized equipment may preclude use solely for animals and, on occasion, veterinary facilities or zoological institutions may wish to utilize human healthcare equipment or facilities.

B. The practices and procedures noted above should be employed to ensure human safety and animal well-being.

VIII. Zoo animals

A. Special care needs to be taken in the transport and care of zoo animals that are venomous (eg, venomous snakes), large (eg, elephant), or carnivorous (eg, tigers, lions).

B. Zoo animals must be accompanied by and contained at all times by trained staff.

C. Contact of animals by HCP not affiliated with the research or clinical activity should be prohibited.

\section{PERSONAL PET VISITATION}

\section{Background}

For the purposes of this document, 'pet' refers to a 'personal pet,' namely a domestic animal that is owned by an individual patient that is not a service animal nor an animal used for animal-assisted activities. Visitation of patients by their own pets potentially offers benefits and challenges. The stronger bond with the pet could accentuate the positive impacts on the patient, and the pre-established relationship between pet and person could reduce the risk of adverse events such as bites and scratches; however, pets and their owners typically do not undergo the same (or any) form of training and scrutiny as compared to animal-assisted activities teams. Further, while visitation with pets can be restricted, in theory, to only the individual patient, in practice, this may not be the case, as pets could encounter various HCP, visitors, and patients during their time in the facility. Therefore, it cannot necessarily be assumed that the implications of visitation of a personal pet are guaranteed to be restricted to an individual patient. While pets are less scrutinized and would not necessarily fulfill the requirements for animal-assisted activities visitation programs, the potentially strong human-animal bond and corresponding potential positive impact on the patient leads many facilities to permit this activity.

\section{Guidance}

I. Each healthcare facility should have a policy regarding the admittance of pet animals into the facility and an individual that oversees the program.

II. Pets should, in general, be prohibited from entering the healthcare facility, including pets of HCP, patients, and visitors. Exceptions can be considered when the healthcare team determines that visitation with a pet would be of benefit to the patient and can be performed with limited 
risk to the patient, other patients, and healthcare facility as a whole. The patient or guardian of the pet should be informed of potential risks, which should be documented in the chart. Situations where visitation with a pet might be considered include the following:

A. Visitation of a terminally ill patient

B. Visitation of a patient who has been hospitalized for a prolonged period of time

C. Visitation of a patient who has a close bond with the animal and where the healthcare team suspects that visitation could improve the patient's physical or mental health

III. Visitation by a pet is different than animal-associated activities or similarly structured activities. Risks from visitation by patients' pets may be increased for the following reasons:

A. There is no formal training of the owner/designee, as with an animal-assisted activities handler(s).

B. Pets have not been temperament tested.

C. Pets do not typically undergo the same degree of health assessment or exclusion practices (eg, age) as compared to animals used in animal-assisted activities.

IV. The degree of restriction should take into consideration the patient's health and mental status, the patient's prognosis, and factors relating to the animal (eg, age).

V. Healthcare facilities that permit a single pet visitation to a patient should have a written policy that includes the following:

A. Approval should be obtained from IPC, as well as the patient's attending physician and nurse. Approval for the visit should be included in the medical record, with details about the animal, as well as the person responsible for the animal's transport and care.

B. Visitation should be restricted to dogs. Animals should be at least 1 year of age and housebroken. Visitation by younger animals could be considered on a case-by-case basis considering the age of the animal, the species, and potential benefits and risks to the patient.

C. Written information should be provided to the animal's owner/designee. This document must specify the following:

1. The approved date, time, and location of visitation.

2. The maximum duration of visitation of one hour.

3. Acceptable and unacceptable practices of the visiting animal are similar to an animal-assisted activities visit.

4. Pre-visitation requirements of the owner/designee are similar to an animal-assisted activities visit.

5. The owner or guardian of the animal is responsible to supervise the animal at all times, prevent contact of other individuals with the animal, promptly clean up any fecal or urine accidents that occur, supervise the visitation process, and report any events (eg, bite, scratch) to HCP.

D. In general, visitation should not be permitted in the following situations:

1. Patients on contact or droplet isolation

2. Patients in an intensive care unit (ICU)
3. Patients whose cognitive status would result in an inability to safely interact with the animal, unless it can be certain that the patient will only be able to see, not touch, the animal.

4. Visitation of patients that have undergone recent solid organ or stem cell transplant or who are significantly immunocompromised.

5. In some situations, these exclusions can be reconsidered by IPC and clinical personnel based on the risk to the patient, others in the healthcare facility or patient's household, and the anticipated benefits to the patient from pet visitation.

VI. An appropriate site for pet visitation should be selected

A. Visitation is best performed outside of the medical facility whenever possible, consistent with facility rules for leaving the facility under proper supervision.

B. If outdoor visitation is not possible, visitation should be performed in a private room.

C. If visitation must occur in a multi-bed room, explicit permission from the roommate (or roommate's guardian) and the roommate's physician must be obtained prior to arrival arriving.

D. Pets should not be fed, given treats, or provided with water during visitation.

E. Animals should be taken directly to the site of visitation, avoiding areas of heavy traffic.

F. The person transporting the animal should prevent the animal from coming into contact with other patients or HCP.

G. The pet should be transported in a carrier whenever possible, or on a leash that is $<2 \mathrm{~m}(6 \mathrm{ft})$ in length.

$\mathrm{H}$. Animals must not be allowed to roam freely in the visitation area.

I. A pet that is disruptive or exhibiting fearful or aggressive behavior (eg, barking, snarling, biting) should be immediately removed. The program coordinator must be notified.

J. The pet should not have the ability to interfere with medical measures (ie, not be able to damage IV tubing).

VII. The patient must perform hand hygiene immediately before and after contact with the animal. It is recommended that a clean additional bed sheet be used to cover the bed if the animal has contact with surface of the bed, and this should be removed and laundered after the animal visit. If a separate sheet is not used, replace any bedding that might be contaminated.

VIII. Pets of HCP should not be brought to a healthcare facility unless part of a formal animal-assisted activities program or for approved visitation of a patient who is a family member.

\section{OTHER USES OF AHC}

\section{Background}

This guidance document has focused on the four major reasons for animal use in healthcare facilities (ie, animal-assisted 
activities, service animals, animals for research, and pet visitation); however, animals may occasionally be used in healthcare facilities for other medical reasons, such as medicinal leeches and larva debridement therapy, educational purposes (eg, zoo and farm animals), and decorative purposes (eg, aquariums). These topics are briefly reviewed and guidance recommendations provided.

\section{Leeches}

Leeches continue to be used in modern medicine in the management of acute problems related to vascular congestion in patients with reimplantation of digits and ears and in reconstruction using cutaneous or muscle flaps. ${ }^{26-30}$ The most common leech used is Hirudo medicinalis. The use of medicinal leeches can increase the risk of wound infections. The most common pathogen is Aeromonas hydrophila, ${ }^{31-34}$ but infection with Vibrio fluvialis has also been reported. ${ }^{35}$ The incidence of wound infection had been reported to be $20 \%{ }^{36}$ Treatment of leeches with ciprofloxacin has been reported to eliminate carriage of Aeromonas spp. ${ }^{37}$ Systemic antibiotics administered to patients have been found to penetrate into leeches and to significantly reduce the rate of $A$. hydrophila isolation compared with controls (ie, $12 \%$ vs $100 \%$ ). ${ }^{38}$

Unused leeches should be maintained by pharmacy. Used engorged leaches should be consider capable of transmitting bloodborne pathogens and should be disposed of as hazardous waste.

\section{Aquariums}

A large number of bacterial infections may be acquired by trauma sustained in water or by injuries caused by water-dwelling animals. ${ }^{39-41}$ The most important of these pathogens are A. hydrophila, Edwardsiella tarda, Erysipelothrix rhusiopathiae, Mycobacterium marinum, Vibrio cholerae nonO1, Vibrio parahaemolyticus, and Vibrio vulnificus. Infections with $M$. marinum can result from cleaning fish tanks. ${ }^{42-51}$ One study reported a public aquarium to be the source of an outbreak of Legionnaires' disease. ${ }^{52}$

Because fish tanks may harbor the aforementioned pathogens, fish tanks generally should be excluded from healthcare facilities and both clinical and non-clinical areas; however, aquariums may be permitted if maintained by trained personnel, use a closed system, and water pumps are designed to prevent aerosalization.

\section{Larvae}

Myiasis is the condition wherein a live vertebrate host is infested by fly larvae (maggots). Healthcare-associated myiasis has been described as generally associated with warm weather, open, unscreened windows, foul-smelling wounds, draining body fluids, and depressed mental status. ${ }^{53}$ In urban and suburban regions of the United States, most cases of myiasis are caused by the relatively benign facultative green blowfly. In one prospective study, only $5 \%$ of the cases were hospitalacquired. Researchers have reviewed the prevention and management of nosocomial myiasis. ${ }^{53,54}$ Larval debridement therapy has been used around the world to promoted wound healing. ${ }^{55}$ Generally, larval debridement therapy has used the disinfected fly larvae of Lucilia sericata in the treatment of wounds resistant to conventional therapy. ${ }^{56,57}$ However, large controlled clinical trials assessing benefits and risks of this therapy have not been performed.

\section{Zoo Animals}

Petting zoos and animal exhibits have been associated with multiple outbreaks. For this reason, in general, farm and other animals should be prohibited from healthcare facilities.

\section{Guidance}

I. If medicinal leeches are used, they should be purchased from a medical supply vendor, maintained in pharmacy, and discarded as regulated medical waste after used (engorged).

a. Consider decolonizing leeches (ie, eliminate carriage of Aeromonas) by feeding leeches on an appropriate antibiotic or prophylactically treating the patient with an appropriate antibiotic.

II. Fish tanks in hospitals should not be allowed due to the risks of infection from maintenance of the fish tank and the possibility of aerosol transmission of Legionella spp. If a facility chooses to have an aquarium, it should be covered, not accessible to patients, maintained by a professional staff, and not placed in a clinical area or in an area with immunocompromised patients. Protocols should be established for aquarium management, including measures to reduce contamination of the environment with aquarium water. Because of the increased risks associated with reptiles (eg, aquatic turtles) ${ }^{62}$ and amphibians (eg, African dwarf frogs), ${ }^{63}$ aquatic reptiles should not be kept in aquariums in healthcare facilities.

III. If maggot debridement therapy is used, only appropriate decolonized flies or fly larvae should be purchased. Maggots should be handled as biohazardous waste after being removed from a patient.

IV. Farm and zoo animals events should be not allowed in a healthcare facility or on healthcare facility property (eg, outside the facility).

\section{AREAS FOR FUTURE RESEARCH}

As the role of AHC evolves, there is a need for research to establish evidence-based guidelines for their management. Carefully conducted randomized controlled trials are needed to assess the benefits of animal-assisted activities in healthcare. 
Additionally, there is a need for the systematic evaluation of risks of animals in healthcare based on the category of use (eg, animal-assisted activities, service animal, research, and personal pet visitation). Prospective tracking of adverse outcomes associated with AHC facilities will help to refine and clarify the approaches recommended in this guidance. In addition, publication of any outbreaks, clusters or infections attributable to the presence of AHC facilities should be encouraged. Finally, prospective studies on optimal infection prevention practices for management of animals in healthcare are needed.

\section{A C KNOW LEDGMENTS}

The Association for Professionals in Infection Control and Epidemiology (APIC) endorses this paper.

Financial support: This study was supported in part by the SHEA Research Network.

Potential conflicts of interest: All authors have no conflicts to disclose that are relevant to this work.

Address correspondence to David J. Weber, MD, MPH; 2163 Bioinformatics, CB \#7030, Chapel Hill, NC, 27599-7030 (dweber@unch.unc.edu).

\section{REFERENCES}

1. Association of American Pet Products. Pet industry market size and ownership statistics. http://www.americanpetproducts.org/ press_industrytrends.asp. Published 2014. Accessed 1 November 2013.

2. Weese JS, Caldwell F, Willey BM, et al. An outbreak of methicillin-resistant Staphylococcus aureus skin infections resulting from horse to human transmission in a veterinary hospital. Vet Microbiol 2006;114:160-164.

3. Lefebvre SL, Golab GC, Christensen E, et al. Guidelines for animal-assisted interventions in health care facilities. Am J Infect Control 2008;36:78-85.

4. Lefebvre SL, Reid-Smith RJ, Waltner-Toews D, Weese JS. Incidence of acquisition of methicillin-resistant Staphylococcus aureus, Clostridium difficile, and other health-care-associated pathogens by dogs that participate in animal-assisted interventions. J Am Vet Med Assoc 2009;234:1404-1417.

5. Oehler RL, Velez AP, Mizrachi M, Lamarche J, Gompf S. Biterelated and septic syndromes caused by cats and dogs. Lancet Infect Dis 2009;9:439-447.

6. Heydemann J, Heydemann JS, Antony S. Acute infection of a total knee arthroplasty caused by Pasteurella multocida: a case report and a comprehensive review of the literature in the last 10 years. Int J Infect Dis 2010;14Suppl 3:e242-e245.

7. Abrahamian FM, Goldstein EJ. Microbiology of animal bite wound infections. Clin Microbiol Rev 2011;24:231-246.

8. Sehulster L, Chinn RY, CDC, HICPAC. Guidelines for environmental infection control in health-care facilities. Recommendations of CDC and the Healthcare Infection Control Practices Advisory Committee (HICPAC). MMWR Recomm Rep 2003;52(RR-10): $1-42$.

9. ADA: Americans With Disabilities Act of 1990. 1990. Pub. L. No. 101-336, 104 Stat. 328. http://www.dol.gov/dol/topic/disability/ ada.htm. Accessed August 16, 2014.
10. Guyatt GH, Oxman AD, Vist GE, et al. GRADE: an emerging consensus on rating quality of evidence and strength of recommendations. BMJ 2008;336:924-926.

11. Centers for Disease Control and Prevention. B Virus (herpes B, monkey B virus, herpesvirus simiae, and herpesvirus B). http://www.cdc.gov/herpesbvirus/firstaid-treatment.html. Published 2014. Accessed August 10, 2014.

12. Serpell J. Animal companions and human well-being: an historical exploration of the value of human-animal relationships. In: Handbook on Animal-Assisted Therapy: Theoretical Foundations and Guidelines for Practice. Waltham, MA: Academic Press, 2000, p. 3-17.

13. Velde B, Cipriani J, Fisher G. Resident and therapist views of animal-assisted therapy: Implications for occupational therapy practice. Austr Occup Ther J 2005;52:43-50.

14. Draper RJ, Gerber GJ, Layng EM. Defining the role of pet animals in psychotherapy. Psychiatr J Univ Ott 1990;15:169-172.

15. Allen DT. Effects of dogs on human health. J Am Vet Med Assoc 1997;210:1136-1139.

16. Friedmann E, Son $\mathrm{H}$. The human-companion animal bond: how humans benefit. Vet Clin North Am Small Anim Pract 2009;39: 293-326.

17. Gammonley J. Animal-assisted therapy: therapeutic interventions. Renton, WA: Delta Society; 1997. Delta Society. ISBN: 1889785032. Accession Number: 12028669.

18. U.S. Department of Justice CRD, Disability Rights Section. ADA Requirements: Service Animals. http://www.ada.gov/service_ animals_2010.htm. Published 2011. Accessed August 2014.

19. Anderson LC, Leary SL, Manning PJ. Rat-bite fever in animal research laboratory personnel. Lab Anim Sci 1983;33:292-294.

20. Davenport DS, Johnson DR, Holmes GP, Jewett DA, Ross SC, Hilliard JK. Diagnosis and management of human B virus (Herpesvirus simiae) infections in Michigan. Clin Infect Dis 1994;19:33-41.

21. Wilson BA, Ho M. Pasteurella multocida: from zoonosis to cellular microbiology. Clin Microbiol Rev 2013;26:631-655.

22. Pedrosa PB, Cardoso TA. Viral infections in workers in hospital and research laboratory settings: a comparative review of infection modes and respective biosafety aspects. Int $J$ Infect Dis 2011;15:e366-e376.

23. Dorsett-Martin WA. Considering Q fever when working with laboratory sheep. Lab Anim (NY) 2010;39:86-89.

24. Saito T, Ohnishi J, Mori Y, Iinuma Y, Ichiyama S, Kohi F. Infection by Chlamydophilia avium in an elderly couple working in a pet shop. J Clin Microbiol 2005;43:3011-3013.

25. Aly R. Ecology and epidemiology of dermatophyte infections. J Am Acad Dermatol 1994;31:S21-S25.

26. Wade JW, Brabham RF, Allen RJ. Medicinal leeches: once again at the forefront of medicine. South Med J 1990;83:1168-1173.

27. Valauri FA. The use of medicinal leeches in microsurgery. Blood Coagul Fibrinolysis 1991;2:185-187.

28. Lineaweaver WC, O'Hara M, Stridde B, Valauri FA, Buncke HJ. Clinical leech use in a microsurgical unit: the San Francisco experience. Blood Coagul Fibrinolysis 1991;2:189-192.

29. Dabb RW, Malone JM, Leverett LC. The use of medicinal leeches in the salvage of flaps with venous congestion. Ann Plast Surg 1992;29:250-256.

30. Wells MD, Manktelow RT, Boyd JB, Bowen V. The medical leech: an old treatment revisited. Microsurgery 1993;14:183-186. 
31. Lineaweaver WC, Hill MK, Buncke GM, et al. Aeromonas hydrophila infections following use of medicinal leeches in replantation and flap surgery. Ann Plast Surg 1992;29:238-244.

32. Lineaweaver WC. Aeromonas hydrophila infections following clinical use of medicinal leeches: a review of published cases. Blood Coagul Fibrinolysis 1991;2:201-203.

33. Sartor C, Limouzin-Perotti F, Legré R, et al. Nosocomial infections with Aeromonas hydrophila from leeches. Clin Infect Dis 2002;35:E1-E5.

34. Levine SM, Frangos SG, Hanna B, Colen K, Levine JP. Aeromonas septicemia after medicinal leech use following replantation of severed digits. Am J Crit Care 2010;19:469-471.

35. Varghese MR, Farr RW, Wax MK, Chafin BJ, Owens RM. Vibrio fluvialis wound infection associated with medicinal leech therapy. Clin Infect Dis 1996;22:709-710.

36. Mercer NS, Beere DM, Bornemisza AJ, Thomas P. Medical leeches as sources of wound infection. Br Med J (Clin Res Ed) 1987;294:937.

37. Mumcuoglu KY, Huberman L, Cohen R, et al. Elimination of symbiotic Aeromonas spp. from the intestinal tract of the medicinal leech, Hirudo medicinalis, using ciprofloxacin feeding. Clin Microbiol Infect 2010;16:563-567.

38. Lineaweaver WC, Furnas H, Follansbee S, et al. Postprandial Aeromonas hydrophila cultures and antibiotic levels of enteric aspirates from medicinal leeches applied to patients receiving antibiotics. Ann Plast Surg 1992;29:245-249.

39. Czachor JS. Unusual aspects of bacterial water-borne illnesses. Am Fam Physician 1992;46:797-804.

40. Lehane L, Rawlin GT. Topically acquired bacterial zoonoses from fish: a review. Med J Aust 2000;173:256-259.

41. Haddad V, Lupi O, Lonza JP, Tyring SK. Tropical dermatology: marine and aquatic dermatology. J Am Acad Dermatol 2009;61: 733-750; quiz 51-52.

42. Vincenzi C, Bardazzi F, Tosti A, Varotti C, Morganti L. Fish tank granuloma: report of a case. Cutis 1992;49:275-276.

43. Gray SF, Smith RS, Reynolds NJ, Williams EW. Fish tank granuloma. BMJ 1990;300:1069-1070.

44. Huminer D, Pitlik SD, Block C, Kaufman L, Amit S, Rosenfeld JB. Aquarium-borne Mycobacterium marinum skin infection. Report of a case and review of the literature. Arch Dermatol 1986;122:698-703.

45. Ries KM, White GL, Murdock RT. Atypical mycobacterial infection caused by Mycobacterium marinum. N Engl J Med 1990;322:633.

46. Ljungberg B, Christensson B, Grubb R. Failure of doxycycline treatment in aquarium-associated Mycobacterium marinum infections. Scand J Infect Dis 1987;19:539-543.

47. Lambertus MW, Mathisen GE. Mycobacterium marinum infection in a patient with cryptosporidiosis and the acquired immunodeficiency syndrome. Cutis 1988;42:38-40.

48. Alinovi A, Vecchini F, Bassissi P. Sporothricoid mycobacterial infection. A case report. Acta Derm Venereol 1993;73:146-147.

49. Brady RC, Sheth A, Mayer T, Goderwis D, Schleiss MR. Facial sporotrichoid infection with Mycobacterium marinum. J Pediatr 1997;130:324-326.

50. Cassetty CT, Sanchez M. Mycobacterium marinum infection. Dermatol Online J 2004;10:21.

51. Schwendiman MN, Johnson RP, Henning JS. Subcutaneous nodules with sporotrichoid spread. Dermatol Online J 2009;15:11.
52. Greig JE, Carnie JA, Tallis GF, et al. An outbreak of Legionnaires' disease at the Melbourne Aquarium, April 2000: investigation and case-control studies. Med J Aust 2004;180:566-572.

53. Lukin LG. Human cutaneous myiasis in Brisbane: a prospective study. Med J Aust 1989;150:237-240.

54. Sherman RA, Roselle G, Bills C, Danko LH, Eldridge N. Healthcare-associated myiasis: prevention and intervention. Infect Control Hosp Epidemiol 2005;26:828-832.

55. Pritchard DI, Nigam Y. Maximising the secondary beneficial effects of larval debridement therapy. J Wound Care 2013;22: 610-11:4-6.

56. Falch BM, de Weerd L, Sundsfjord A. [Maggot therapy in wound management]. Tidsskr Nor Laegeforen 2009;129:1864-1867.

57. Chan DC, Fong DH, Leung JY, Patil NG, Leung GK. Maggot debridement therapy in chronic wound care. Hong Kong Med J 2007;13:382-386.

58. National Association of State Public Health Veterinarians IcN, (CDC) CfDCaP. Compendium of measures to prevent disease associated with animals in public settings, 2011: National Association of State Public Health Veterinarians, Inc. MMWR Recomm Rep 2011;60(RR-04):1-24.

59. Bender JB, Shulman SA, subcommittee AiPC, Veterinarians NAoSPH. Reports of zoonotic disease outbreaks associated with animal exhibits and availability of recommendations for preventing zoonotic disease transmission from animals to people in such settings. J Am Vet Med Assoc 2004;224:1105-1109.

60. Pickering LK, Marano N, Bocchini JA, Angulo FJ, Diseases CoI. Exposure to nontraditional pets at home and to animals in public settings: risks to children. Pediatrics 2008;122:876-886.

61. Stirling J, Griffith M, Dooley JS, et al. Zoonoses associated with petting farms and open zoos. Vector Borne Zoonotic Dis 2008; 8:85-92.

62. (CDC) CfDCaP. Notes from the field: outbreak of salmonellosis associated with pet turtle exposures-United States, 2011. MMWR 2012;61:79.

63. Mettee Zarecki SL, Bennett SD, Hall J. US outbreak of human Salmonella infections associated with aquatic frogs, 2008-2011. Pediatrics 2013;131:724-731.

64. Lefebvre SL, Waltner-Toews D, Peregrine AS, et al. Prevalence of zoonotic agents in dogs visiting hospitalized people in Ontario: implications for infection control. J Hosp Infect 2006;62: 458-466.

65. Scott GM, Thomson R, Malone-Lee J, Ridgway GL. Crossinfection between animals and man: possible feline transmission of Staphylococcus aureus infection in humans? J Hosp Infect 1988;12:29-34.

66. Lyons RW, Samples CL, DeSilva HN, Ross KA, Julian EM, Checko PJ. An epidemic of resistant Salmonella in a nursery. Animal-to-human spread. JAMA 1980;243:546-547.

67. Richet HM, Craven PC, Brown JM, et al. A cluster of Rhodococcus (Gordona) Bronchialis sternal-wound infections after coronary-artery bypass surgery. N Engl J Med 1991;324:104-109.

68. Chang HJ, Miller HL, Watkins N, et al. An epidemic of Malassezia pachydermatis in an intensive care nursery associated with colonization of health care workers' pet dogs. $N$ Engl J Med 1998;338:706-711.

69. Mossovitch M, Mossovitch B, Alkan M. Nosocomial dermatophytosis caused by Microsporum canis in a newborn department. Infect Control 1986;7:593-595. 
70. Snider R, Landers S, Levy ML. The ringworm riddle: an outbreak of Microsporum canis in the nursery. Pediatr Infect Dis J 1993;12:145-148.

71. Abate SV, Zucconi M, Boxer BA. Impact of canine-assisted ambulation on hospitalized chronic heart failure patients' ambulation outcomes and satisfaction: a pilot study. J Cardiovasc Nurs 2011;26:224-230.

72. Banks MR, Banks WA. The effects of animal-assisted therapy on loneliness in an elderly population in long-term care facilities. J Gerontol A Biol Sci Med Sci 2002;57:M428-M432.

73. Barak Y, Savorai O, Mavashev S, Beni A. Animal-assisted therapy for elderly schizophrenic patients: a one-year controlled trial. Am J Geriatr Psychiatry 2001;9:439-442.

74. Barker SB, Pandurangi AK, Best AM. Effects of animal-assisted therapy on patients' anxiety, fear, and depression before ECT. J ECT 2003;19:38-44.

75. Barker SB, Dawson KS. The effects of animal-assisted therapy on anxiety ratings of hospitalized psychiatric patients. Psychiatr Serv 1998;49:797-801.

76. Beck CE, Gonzales F, Sells CH, Jones C, Reer T, Zhu YY. The effects of animal-assisted therapy on wounded warriors in an Occupational Therapy Life Skills program. US Army Med Dep J 2012;38-45.

77. Brodie SJ, Biley FC. An exploration of the potential benefits of pet-facilitated therapy. J Clin Nurs 1999;8:329-337.

78. Chu CI, Liu CY, Sun CT, Lin J. The effect of animal-assisted activity on inpatients with schizophrenia. J Psychosoc Nurs Ment Health Serv 2009;47:42-48.

79. Cole KM, Gawlinski A, Steers N, Kotlerman J. Animal-assisted therapy in patients hospitalized with heart failure. Am J Crit Care 2007;16:575-585; quiz 86; discussion 87-8.
80. Edwards NE, Beck AM. Animal-assisted therapy and Nutrition in Alzheimer's disease. West J Nurs Res 2002;24:697-712.

81. Edwards NE, Beck AM, Lim E. Influence of aquariums on resident behavior and staff satisfaction in dementia units. West $J$ Nurs Res 2014;36:1309-1322.

82. Jorgenson J. Therapeutic use of companion animals in health care. Image J Nurs Sch 1997;29:249-254.

83. Kamioka H, Okada S, Tsutani K, et al. Effectiveness of animalassisted therapy: a systematic review of randomized controlled trials. Complement Ther Med 2014;22:371-390.

84. Levine GN, Allen K, Braun LT, et al. Pet ownership and cardiovascular risk: a scientific statement from the American Heart Association. Circulation 2013;127:2353-2363.

85. Marcus DA. The science behind animal-assisted therapy. Curr Pain Headache Rep 2013;17:322.

86. Moretti F, De Ronchi D, Bernabei V, et al. Pet therapy in elderly patients with mental illness. Psychogeriatrics 2011;11:125-129.

87. Nepps P, Stewart CN, Bruckno SR. Animal-assisted activity: effects of a complementary intervention program on psychological and physiological variables. J Evid Based Complementary Altern Med 2014;19:211-215.

88. Nordgren L, Engström G. Animal-assisted intervention in dementia: effects on quality of life. Clin Nurs Res 2014;23:7-19.

89. Sobo EJ, Seid M, Reyes Gelhard L. Parent-identified barriers to pediatric health care: a process-oriented model. Health Serv Res 2006;41:148-172.

90. Swall A, Ebbeskog B, Lundh Hagelin C, Fagerberg I. Can therapy dogs evoke awareness of one's past and present life in persons with Alzheimer's disease? Int J Older People Nurs 2014; May 10 [Epub ahead of print].

91. Willis DA. Animal therapy. Rehabil Nurs 1997;22:78-81. 